\title{
One-step synthesis of samarium-doped ceria and its CO catalysis
}

\author{
TIAN DENG, CHONGRONG ZHANG, YUYUAN XIAO, ANRAN XIE, YUE PANG and \\ YANZHAO YANG*
}

Key Laboratory for Special Functional Aggregate Materials of Education Ministry, School of Chemistry and Chemical Engineering, Shandong University, Jinan 250100, PR China

MS received 16 February 2015; accepted 29 April 2015

\begin{abstract}
The samarium-doped ceria (SDC) nanospheres were prepared by the one-step hydrothermal method and characterized by transmission electron microscope, scanning electron microscope, powder X-ray diffraction, X-ray photoelectron spectroscopy, energy-dispersive spectrometer and Raman spectra. According to the results, samarium was doped into the lattice successfully. The as-prepared samples were dispersed well and the average diameter was $60 \mathrm{~nm}$. It showed better catalytic performance than pure ceria and the most appropriate concentration of doping was found.
\end{abstract}

Keywords. Nanomaterial; hydrothermal method; characterization; CO oxidization; one-step synthesis.

\section{Introduction}

The study of samarium-doped cerium oxide (SDC) has been flourishing since its excellent electric properties were discovered in the 1980s. ${ }^{1}$ At present SDC is applied widely as electrode materials of solid oxide fuel cells (SOFCs) and catalyst of oxidation reactions. ${ }^{2}$ It has been reported that SDC improves the conductivity of electrode, ${ }^{3,4}$ decreases the work temperature of battery ${ }^{4,5}$ and increases the carbon-tolerance ability of the electrodes. ${ }^{6}$ All these properties make SDC to become an ideal material for electrodes. Moreover, it shows excellent catalytic performance in many important organic reactions, such as benzyl alcohol oxidation ${ }^{7}$ and allylic oxidation of cyclohexene. ${ }^{8}$ While $\mathrm{CO}$ oxidation is a crucial inorganic reaction in environmental protection, the traditional cerium catalyst, such as gold-palladium-supported nanoparticles ${ }^{9}$ and palladium-supported nanowires, ${ }^{10}$ is expensive to spread their applications and it is useful to study the catalytic performance of CO oxidation of SDC, which is effective and more economic.

So far various methods have been used for doping samarium to cerium oxide. Co-precipitation and hydrothermal method are used for preparing nanoscale SDC such as nanorods, ${ }^{11}$ nanowires, ${ }^{12}$ nanoparticles, ${ }^{8}$ while the procedure of synthesis was complicated and not suitable for industrial manufacture. Hence it still remains challenging to establish a one-pot facile synthesis for the preparation of doped ceria with uniform size and shape. In our current work, a series of $\mathrm{Sm}^{3+}$-doped $\mathrm{CeO}_{2}$

*Author for correspondence (yzhyang@sdu.edu.cn) nanospheres have been first prepared via a one-step, mild and environmental-friendly hydrothermal process and the products have better catalytic performance and a large surface.

\section{Experimental}

\subsection{Materials}

Cerium(III) chloride heptahydrate $\left[\mathrm{CeCl}_{3} \cdot 7 \mathrm{H}_{2} \mathrm{O}, \geq 99.99 \%\right]$ was purchased from Aladdin Industrial Inc. Samarium(III) oxide $\left(\mathrm{Sm}_{2} \mathrm{O}_{3}\right)$, polyvinylpyrrolidone (PVP, K30), potassium chlorate $\left(\mathrm{KClO}_{3}\right)$, N,N-dimethylformamide (DMF), hydrochloric acid $(\mathrm{HCl}, 36.0-38.0 \%)$ were obtained from Sinopharm Chemical Reagent Co. Ltd. All the above reagents were of analytical grade and were used without further purification. Deionized water was used throughout. $\mathrm{HCl}$ solution with a concentration of $1 \mathrm{M}$ was obtained by diluting commercial $\mathrm{HCl}$ solution $(\mathrm{HCl}, 36.0-38.0 \%)$.

\subsection{The synthesis of $\mathrm{Sm}^{3+}$-doped $\mathrm{CeO}_{2}$ nanoparticles $\left(P_{1}-P_{6}\right)$}

In total, $0.15 \mathrm{~g}$ of $\mathrm{CeCl}_{3} \cdot 7 \mathrm{H}_{2} \mathrm{O}$, different masses $(0.01$, $0.02,0.03,0.04,0.05,0.06 \mathrm{~g}$ ) of $\mathrm{Sm}_{2} \mathrm{O}_{3}, 0.178 \mathrm{~g}$ of PVP and $0.250 \mathrm{~g} \mathrm{KClO}_{3}$ were dissolved in $16 \mathrm{ml}$ of deionized water under vigorous magnetic stirring. Then $\mathrm{HCl}$ (1 M) was added into the solution under vigorous magnetic stirring until $\mathrm{pH}$ of solution is about 3 . Then $0.6 \mathrm{ml}$ of $\mathrm{N}, \mathrm{N}$ dimethylformamide was added into the solution under continuous stirring for $15 \mathrm{~min}$. The as-formed solution was transferred into a Teflon-lined autoclave of $20 \mathrm{ml}$ 
capacity and heated for $4 \mathrm{~h}$ at $180^{\circ} \mathrm{C}$. After the autoclave was cooled to room temperature naturally, light yellow products were collected and washed with deionized water for three times. Finally, the products were washed with absolute ethanol three times and dried in an electric oven at $60^{\circ} \mathrm{C}$ overnight, and then calcined at $300^{\circ} \mathrm{C}$ for $200 \mathrm{~min}$. The above products with different $\mathrm{Sm}^{3+}$ doping concentrations were labelled as $\mathrm{P}_{1}-\mathrm{P}_{6}$ samples.

\subsection{Characterization}

The phase purity of the sample was examined by X-ray diffraction (XRD) with a Bruker D8 Advance X-ray diffractometer with $\mathrm{CuK} \alpha$ radiation $(\lambda=0.15418 \mathrm{~nm})$ in the $2 \theta$ range from $10^{\circ}$ to $80^{\circ}$. The microstructure and morphology of the products were characterized using a transmission electron microscope (TEM, JEM 100-CXII, $80 \mathrm{kV}$ ), a high-resolution transmission electron microscope (HRTEM, JEM-2100, $200 \mathrm{kV}$ ) and a field-emission scanning electron microscope (FE-SEM, Hitachi, S4800) equipped with an energy-dispersive X-ray spectrometer (EDS). X-ray photoelectron spectra were recorded with a PHI 5300 X-ray photoelectron spectrometer with a standard AlK $\alpha$ source. The charging of the samples was corrected by referencing all of the energies to the $\mathrm{C} 1 \mathrm{~s}$ peak energy set at $284.7 \mathrm{eV}$, arising from the aliphatic hydrocarbon $(\mathrm{C}-\mathrm{C})$ chains. Raman data were obtained using a Horiba Jobin Yvon HRT800 spectrometer with an inverted microscope, using a $633 \mathrm{~nm}$ laser line as an excitation source. $\mathrm{N}_{2}$ adsorption-desorption isotherms were measured with a Quadra-Sorb S1 apparatus at $77 \mathrm{~K}$. The surface areas were calculated by the Brunauer-EmmettTeller (BET) method, and the pore size distribution was calculated from the desorption branch using the BarettJoyner-Halenda (BJH) theory.

\subsection{Measurement of catalytic activity}

The catalytic activity of the as-obtained samples was evaluated by a continuous flow fixed-bed microreactor operating under atmospheric pressure. In a typical experiment, catalyst particles $(50 \mathrm{mg})$ were placed in the reactor. The reactant gases $\left(1 \% \mathrm{CO}, 10 \% \quad \mathrm{O}_{2}\right.$ and $\left.89 \% \mathrm{~N}_{2}\right)$ passed through the reactor at a rate of $60 \mathrm{ml} \mathrm{min}^{-1}$. The composition of the gas exiting the reactor was analysed with an online infrared gas analyzer (Gasboard-3121, China Wuhan Cubic Co.), which simultaneously detects $\mathrm{CO}$ and $\mathrm{CO}_{2}$ with a resolution of $10 \mathrm{ppm}$. The results were further confirmed with a Shimadzu gas chromatograph (GC-14).

\section{Results and discussion}

The phase purity of the product was examined by the XRD pattern. Figure 1 shows the typical diffraction

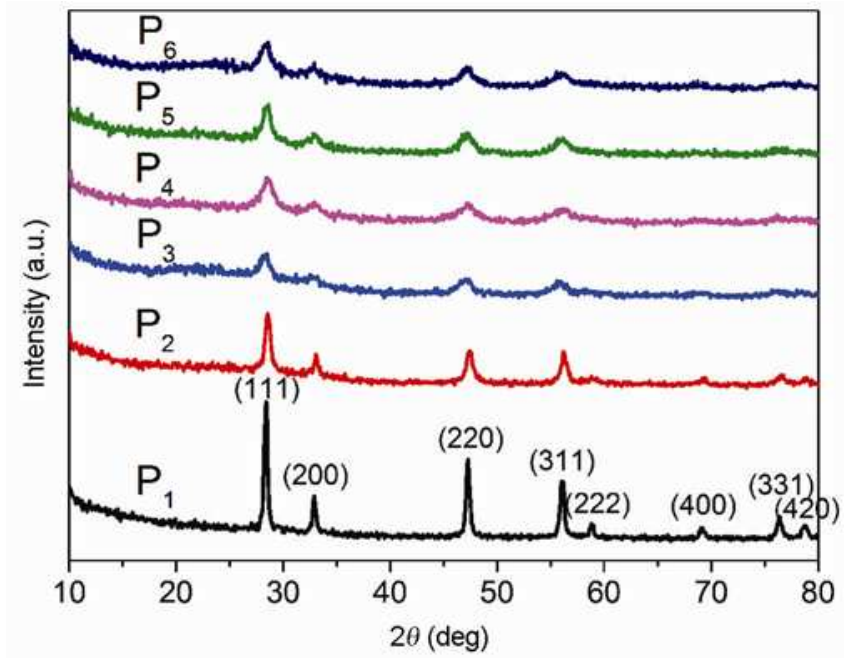

Figure 1. XRD patterns of the as-obtained samples with different Sm-doped amounts: $\mathrm{P}_{1}(0.01 \mathrm{~g}), \mathrm{P}_{2}(0.02 \mathrm{~g}), \mathrm{P}_{3}(0.03 \mathrm{~g})$, $\mathrm{P}_{4}(0.04 \mathrm{~g}), \mathrm{P}_{5}(0.05 \mathrm{~g})$ and $\mathrm{P}_{6}(0.06 \mathrm{~g})$.

patterns of the as-prepared $\mathrm{CeO}_{2}$ products, including the series of $\mathrm{Sm}^{3+}$-doped $\mathrm{CeO}_{2}$ samples $\left(\mathrm{P}_{1}-\mathrm{P}_{6}\right)$. The diffraction peaks of all the products illustrated that they can be well indexed to a pure phase of face-centred cubic ceria structures (JCPDS no. 34-0394). Moreover, the diffraction peak of $\mathrm{Sm}_{2} \mathrm{O}_{3}$ did not appear, which means instead of form binary metal oxide with $\mathrm{CeO}_{2}$, the $\mathrm{Sm}^{3+}$ is doped into $\mathrm{CeO}_{2}$ lattice. Furthermore, it can be noticed that the peaks of $\mathrm{P}_{1}$ and $\mathrm{P}_{2}$ are much higher and narrower than the peaks of $\mathrm{P}_{3}-\mathrm{P}_{6}$, which means nanospheres of $\mathrm{P}_{1}$ and $\mathrm{P}_{2}$ are more regular than that of $\mathrm{P}_{3}-\mathrm{P}_{6}$ and the particle diameter of $\mathrm{P}_{3}-\mathrm{P}_{6}$ are smaller and have a broader distribution. ${ }^{13}$

The morphology and structures of the as-prepared $\mathrm{P}_{1}-\mathrm{P}_{6}$ samples are explored by transmission electron microscopy (TEM). The TEM image (figure 2) shows the products consist of well-dispersed uniform nanospheres with a narrow size range, and the average diameter of the spheres is $60 \mathrm{~nm}$. The boundaries of the nanospheres are smooth and well formed. As the doping amount increase, the size of the nanospheres become smaller (from 50 to $70 \mathrm{~nm}$ ) and the structure of them become looser and more regular because the colour of TEM images become lighter and more homogeneous. It is because that $\mathrm{Sm}^{3+}$ disturbed the crystallization of cerium oxide and cause more defect on the grain boundary as mentioned above.

The phenomenon that the XRD peaks of $\mathrm{P}_{1}$ and $\mathrm{P}_{2}$ are much higher and narrower than the peaks of $\mathrm{P}_{3}-\mathrm{P}_{6}$ can also be supported by the TEM images (figure 2). It can be easily observed from the images that $\mathrm{P}_{1}$ and $\mathrm{P}_{2}$ are made of solid nanospheres with clear boundaries, while the nanospheres of $\mathrm{P}_{3}-\mathrm{P}_{6}$ were loose packed and no obvious boundaries could be observed. It may be resulted from that samarium ion doping inhibited the phase transformation from amorphous to fluorite crystals in the solid ${ }^{13}$ and the crystal defects become more severe as the amount of $\mathrm{Sm}^{3+}$ grow. 

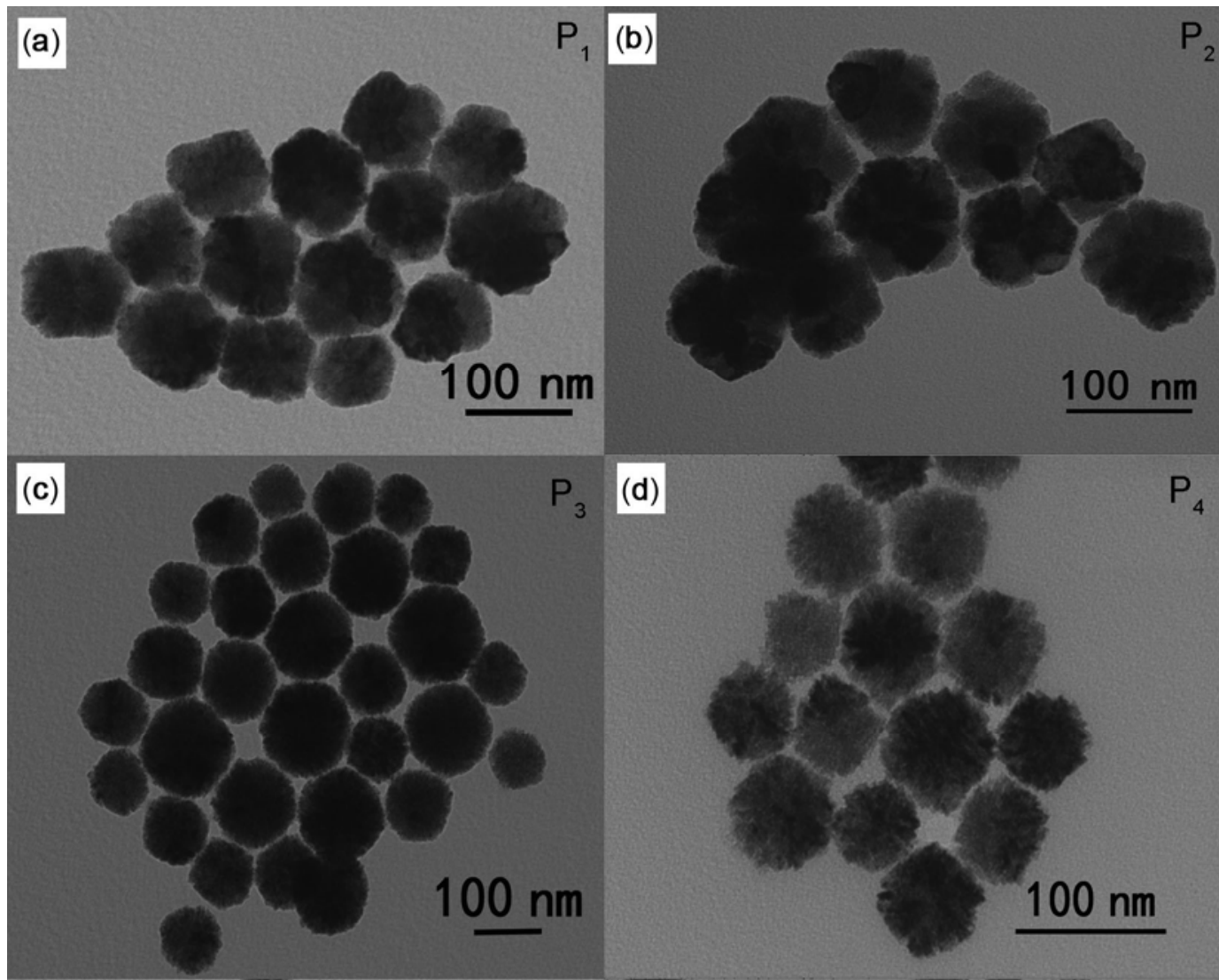

(d)
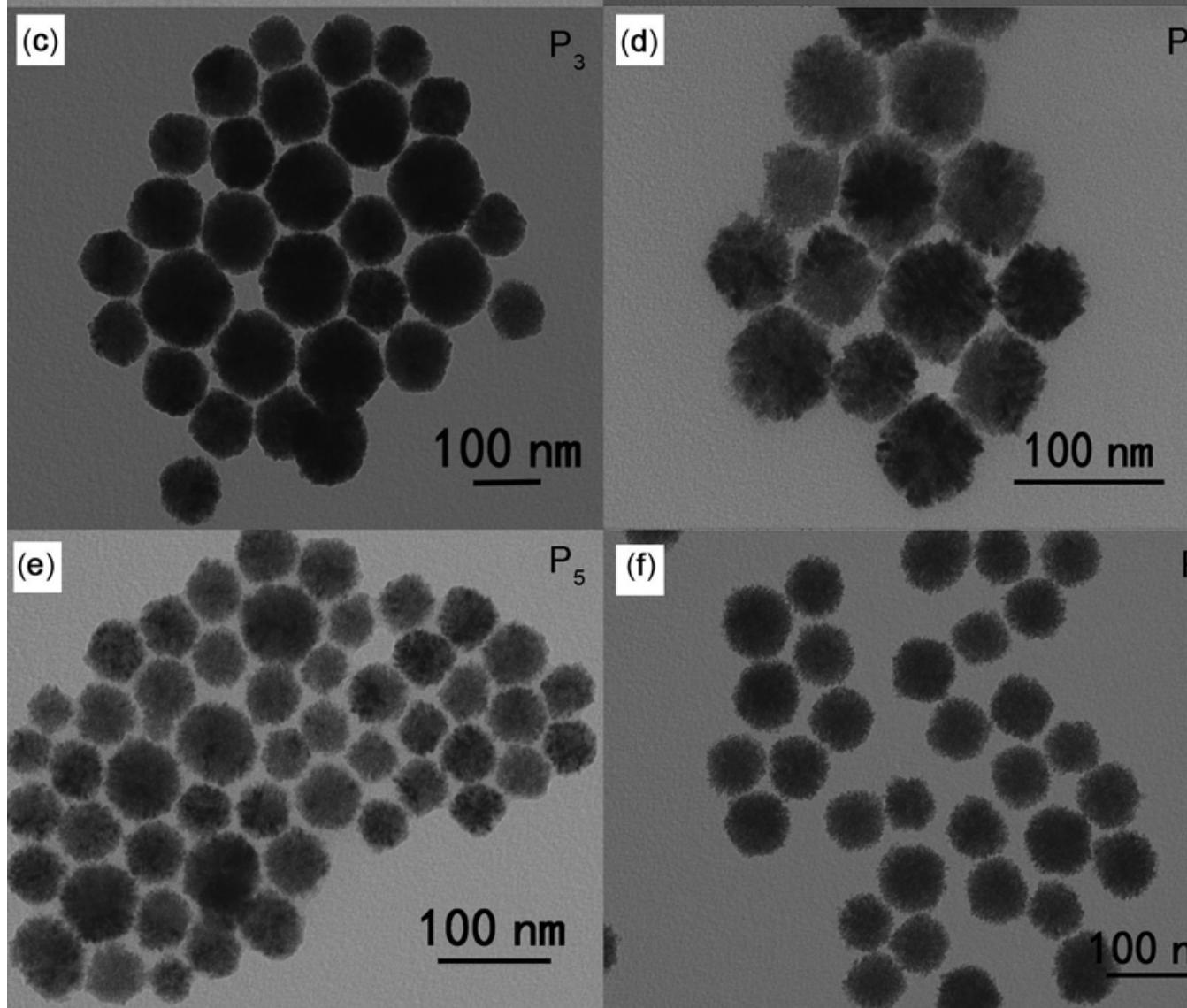

(f)

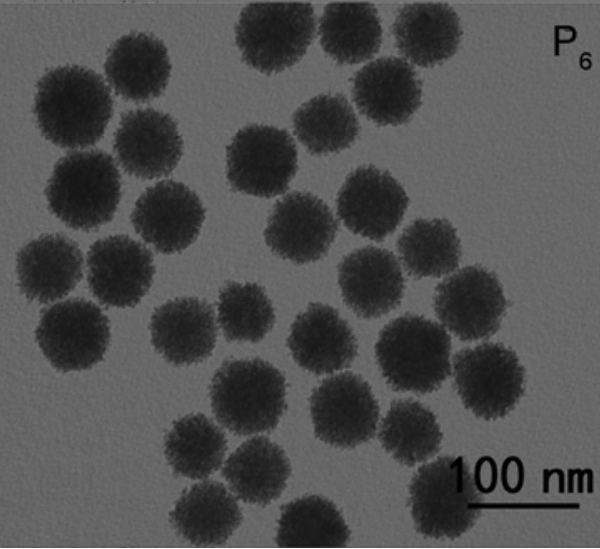

Figure 2. (a-f) TEM images of $\mathrm{P}_{1}-\mathrm{P}_{6}$ samples.

The polycrystalline properties provided by the selected area electron diffraction (SAED) patterns from the HRTEM results of $\mathrm{P}_{3}$ demonstrate that the products are formed of many small nanoparticles. The interplanar spacing of the two planes is about $0.276 \mathrm{~nm}$ (figure 3a), which are comparable to the values of the (200) plane of face-centred phase ceria. The result of scanning electron microscopy (SEM) agreed well with the result of TEM.

Elemental composition of the products was analysed by EDS. From figure 4 several peaks of $\mathrm{Ce}, \mathrm{Sm}$ and $\mathrm{O}$, respectively, can be seen, and the chemical formulas in this paper are based on the results of EDS test. When $\mathrm{Sm}_{2} \mathrm{O}_{3}$ was added in the reaction, the rate of $\mathrm{Sm}$ in products increased (shown in table 1 ).

The elementary composition and chemical valence on the surface of the as-prepared $\mathrm{P}_{3}\left(\mathrm{Ce}_{0.76} \mathrm{Sm}_{0.24} \mathrm{O}_{2}\right)$ particulate powders were detected by X-ray photoelectron spectra (XPS). Figure 5a shows the XPS survey spectrum of as-prepared product, which indicate the existence of cerium $\left(\mathrm{Ce} 3 \mathrm{~d}_{5 / 2}\right.$ and $\left.\mathrm{Ce} 3 \mathrm{~d}_{3 / 2}\right)$, samarium $\left(\mathrm{Sm} 4 \mathrm{~d}_{5 / 2}\right)$ and oxygen $(\mathrm{O} 1 \mathrm{~s})$ elements. The carbon peak mainly originates from organic molecules adsorbed on the sample surface. The XPS spectrum of Ce 3d (figure 5c) shows two characteristic peaks of $\mathrm{Ce} 3 \mathrm{~d}_{3 / 2}$ and $\mathrm{Ce} 3 \mathrm{~d}_{5 / 2}$, which are in agreement with a previous report on $\mathrm{Ce}^{4+}$ ion. ${ }^{14,15}$ 


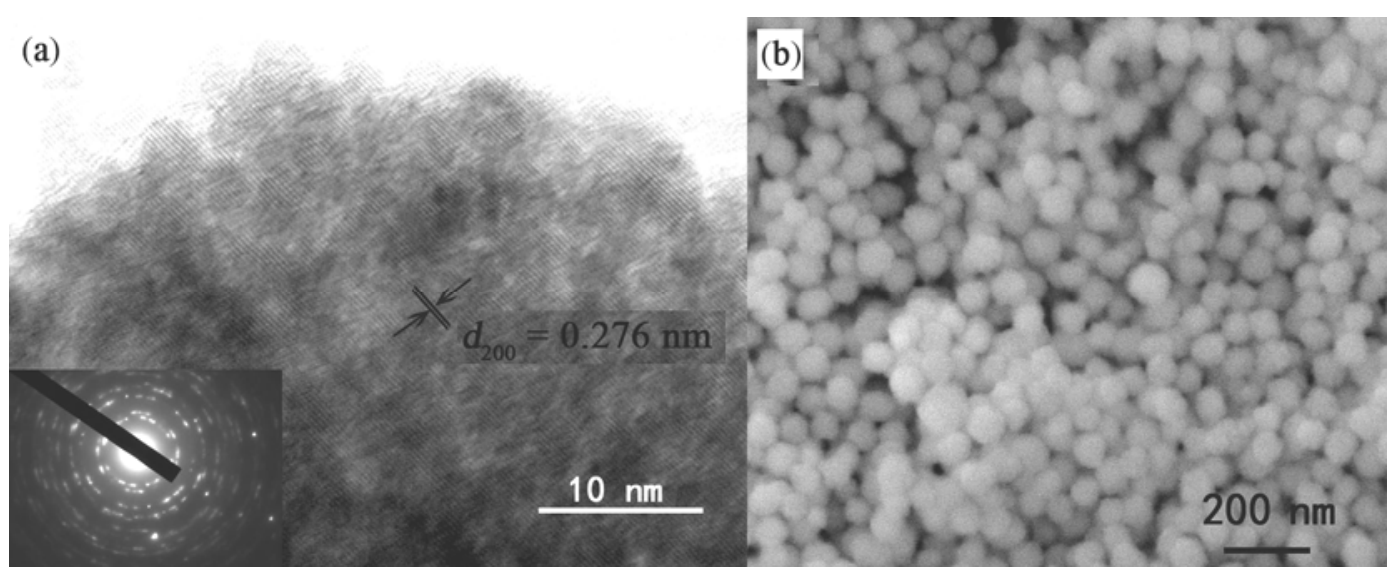

Figure 3. (a) HRTEM and (b) SEM images of $\mathrm{P}_{3}$.

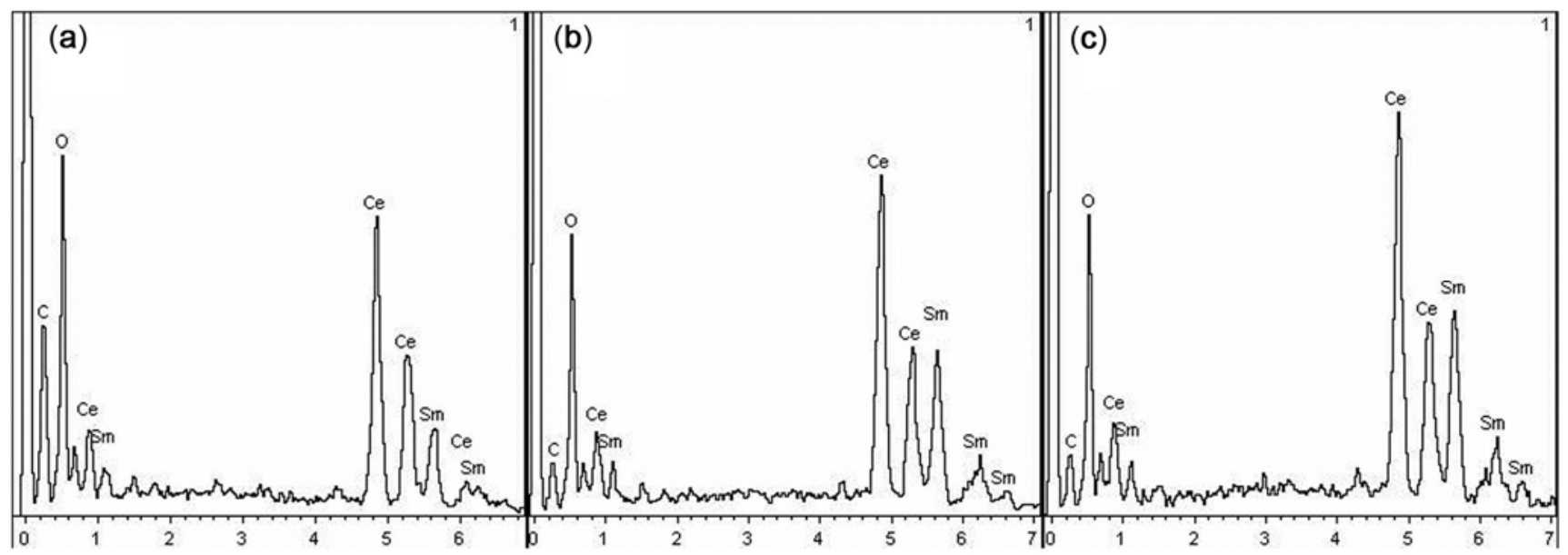

Figure 4. EDS patterns of $\mathrm{P}_{1}, \mathrm{P}_{3}$ and $\mathrm{P}_{5}$.

Table 1. Elemental composition of $\mathrm{P}_{1}-\mathrm{P}_{6}$.

\begin{tabular}{lcrc}
\hline Atomic percent & $\mathrm{Ce}$ & $\mathrm{Sm}$ & $\mathrm{O}$ \\
\hline $\mathrm{P}_{1}\left(\mathrm{Ce}_{0.9} \mathrm{Sm}_{0.1} \mathrm{O}_{2}\right)$ & 21.62 & 2.55 & 75.83 \\
$\mathrm{P}_{2}\left(\mathrm{Ce}_{0.85} \mathrm{Sm}_{0.15} \mathrm{O}_{2}\right)$ & 32.60 & 5.98 & 61.41 \\
$\mathrm{P}_{3}\left(\mathrm{Ce}_{0.76} \mathrm{Sm}_{0.24} \mathrm{O}_{2}\right)$ & 24.48 & 7.65 & 67.87 \\
$\mathrm{P}_{4}\left(\mathrm{Ce}_{0.72} \mathrm{Sm}_{0.28} \mathrm{O}_{2}\right)$ & 19.50 & 7.58 & 72.92 \\
$\mathrm{P}_{5}\left(\mathrm{Ce}_{0.73} \mathrm{Sm}_{0.27} \mathrm{O}_{2}\right)$ & 24.82 & 9.39 & 65.80 \\
$\mathrm{P}_{6}\left(\mathrm{Ce}_{0.7} \mathrm{Sm}_{0.3} \mathrm{O}_{2}\right)$ & 23.49 & 10.08 & 66.43 \\
\hline
\end{tabular}

As shown in figure $5 \mathrm{~d}$, the two peaks correspond to the characteristic $\mathrm{Sm} 3 \mathrm{~d}_{5 / 2}$ and $\mathrm{Sm} 3 \mathrm{~d}_{3 / 2}$ signals. ${ }^{16-18}$ No evidence of other oxidation states of samarium was found. ${ }^{19}$ But the binding energy for $\mathrm{Sm} 3 \mathrm{~d}_{5 / 2}$ is $1083.4 \mathrm{eV}$ in $\mathrm{Sm}_{2} \mathrm{O}_{3}$ (Sm-O bonds), ${ }^{17}$ which is little different from $\operatorname{Sm~} 3 \mathrm{~d}_{5 / 2}$ in $\mathrm{P}_{3}$. This phenomenon indicated that the chemical environment surrounding samarium had changed a little because of the doping. ${ }^{20}$ These results suggest that cerium atoms have been partly substituted by the doped $\mathrm{Sm}^{3+}$. In the O 1s XPS spectrum (figure $5 \mathrm{~b}$ ), the main peak centred at $529.05 \mathrm{eV}$ can be indexed to the lattice oxygen in crystalline $\mathrm{CeO}_{2}$. The shoulder peak at around $531.35 \mathrm{eV}$ corresponds to the appearance of defective oxygen regions or adsorbed oxygen, indicating a better capacity for oxygen storage, which is also known to be related to the activity of oxidization reaction. ${ }^{21}$

Raman scattering is used to study doping effects on doping nanomaterial. Figure 6 shows the Raman spectra of $\mathrm{P}_{1}-\mathrm{P}_{6}$. For pure ceria, strong band at $460 \mathrm{~cm}^{-1}$ is due to the $F_{2 \mathrm{~g}}$ vibration of $\mathrm{CeO}_{2}$ fluorite-type lattice. ${ }^{22-24}$ Compared with the pure ceria, the doped ceria have the following characters: the peaks have negative frequency shift and become less symmetric, while their intensity change as the doping amount increase. The red shift and increasing width of peaks of $\mathrm{P}_{1}-\mathrm{P}_{6}$ are due to the lattice defects, ${ }^{25-27}$ which consist of oxygen vacancies and the dilation of the lattice and different doping amount cause different red shifts. The tendency concluded from figure 6 is that the peak values first decrease, and then increase as the $\mathrm{Sm}^{3+}$ doping concentration increase. It 

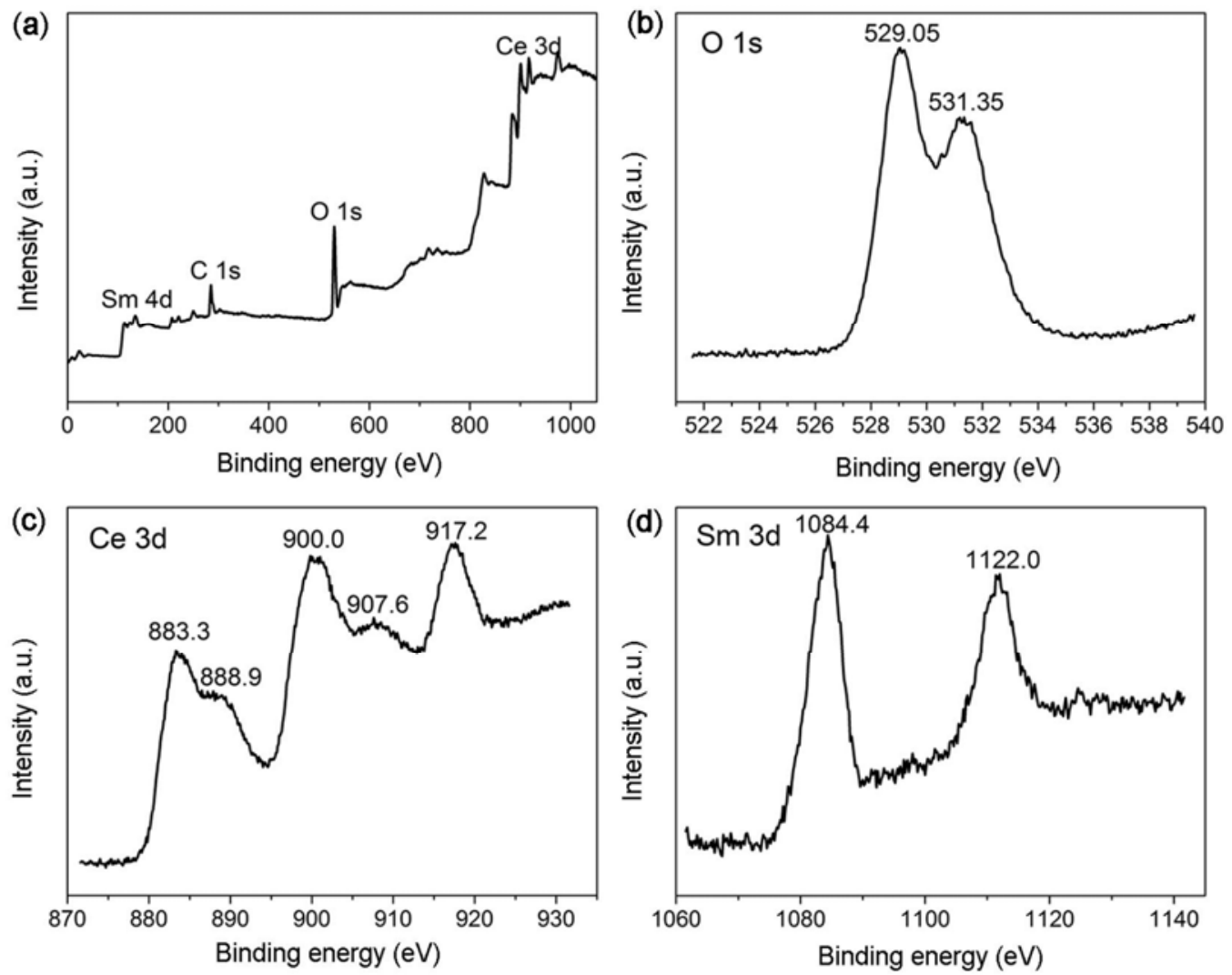

Figure 5. XPS pattern of $\mathrm{P}_{3}\left(\mathrm{Ce}_{0.76} \mathrm{Sm}_{0.24} \mathrm{O}_{2}\right)$ : (a) survey spectrum, (b) $\mathrm{O} 1 \mathrm{~s}$, (c) Ce $3 \mathrm{~d}$ and (d) $\mathrm{Sm} 3 \mathrm{~d}$.

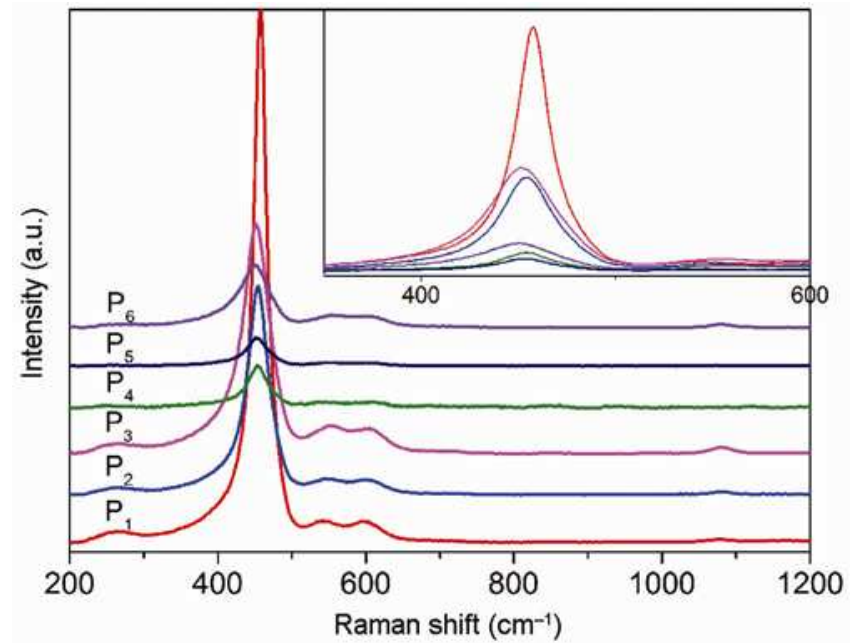

Figure 6. Raman spectra of $\mathrm{P}_{1}-\mathrm{P}_{6}$.

was noticed that the product with highest peak shift is $\mathrm{P}_{3}$, and it also has the most intensive broad double peaks around 552 and $603 \mathrm{~cm}^{-1}$. There is a positive correlation between the intensity of these peaks and the amount of oxygen vacancies, ${ }^{23}$ hence it can be deduced that $\mathrm{P}_{3}$ has the most oxygen vacancies. This means the outstanding catalytic performance is not only because of the surface area, but also the oxygen vacancies. Also, it is found that there is an overtone band at around $1080 \mathrm{~cm}^{-1}$ in Raman spectra, which is due to the second-order longitudinal optical (2 LO) mode. ${ }^{28,29}$ The 2 LO band activation is due to the multiphonon relaxation by the resonance Raman effect. ${ }^{30}$ As for the decreasing intensity of the peaks, it is because of the heavier yellow of the products as the doping amount increase. ${ }^{23}$

The nitrogen sorption measurement was performed to further the research on the porous structure of $\mathrm{P}_{3}$ (shown in figure 7). The adsorption isotherm in the lowrelative-pressure region is attributed to the surface area of the nanospheres, whereas the hysteresis loops are from the narrow pores inside the nanospheres, which may result from structure distortion of microspheres caused by Sm doping. The BET surface area of $\mathrm{P}_{3}$ spherical aggregates was calculated to be $96.241 \mathrm{~m}^{2} \mathrm{~g}^{-1}$. The corresponding pore size distribution curve calculated from the desorption branch by the $\mathrm{BJH}$ method demonstrates that most of the pore diameters range from 0 to $4 \mathrm{~nm}$.

\section{Catalytic performance}

Ceria has been widely used as a three-way catalyst in automobile exhaust systems for its high oxygen storage capacity and it is widely accepted that the catalytic processes is mainly related to the adsorption and desorption of gas molecules on the surface of catalyst. The dope of $\mathrm{Sm}^{3+}$, which has the similar radius as $\mathrm{Ce}^{3+/ 4+}$ but 


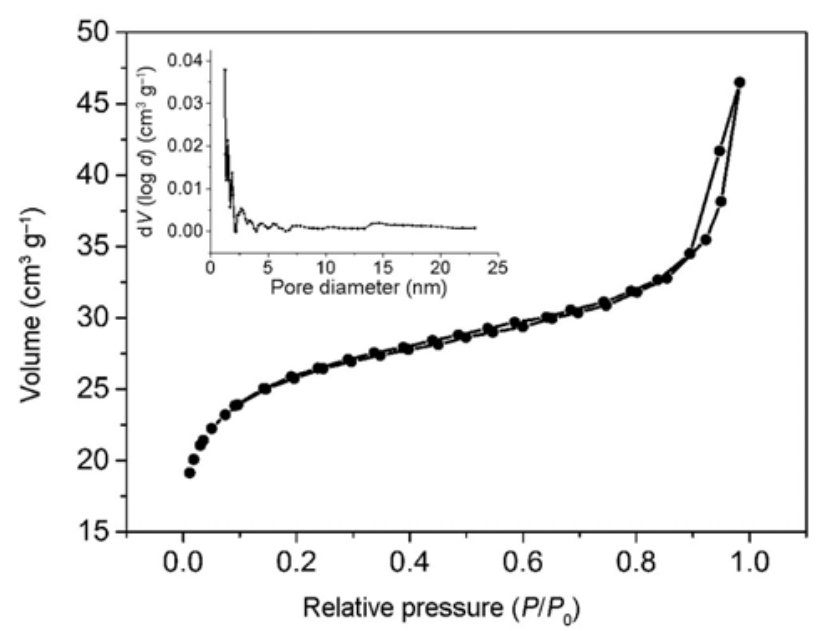

Figure 7. $\mathrm{N}_{2}$ adsorption-desorption isotherms of $\mathrm{P}_{3}$. Inset is the corresponding $\mathrm{BJH}$ pore size distribution curve.

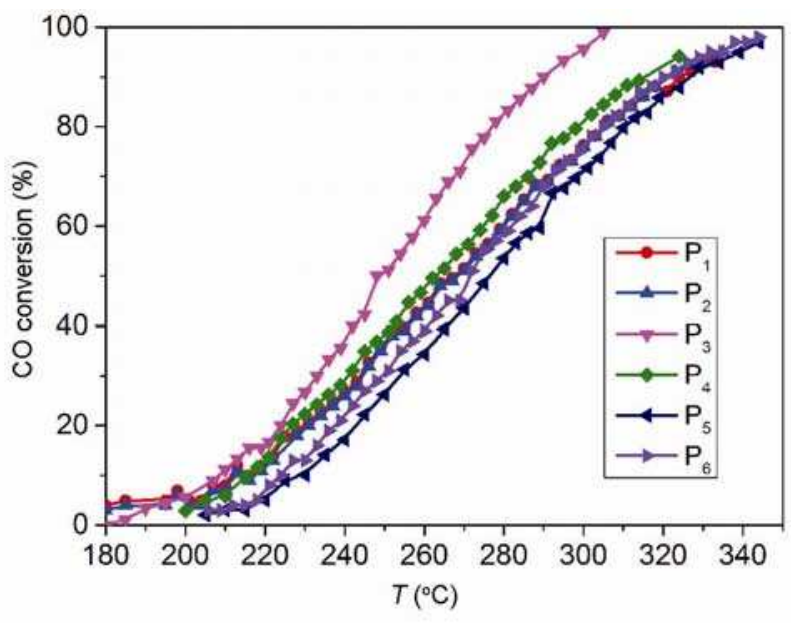

Figure 8. Catalytic performance of products with different doping amounts.

different valence, can cause lattice defect, thus enhance the oxygen storage capacity and improve the catalytic performance. The products with different doping amounts were evaluated for their catalytic activity towards $\mathrm{CO}$ oxidation reaction. Compared with traditional cerium catalyst, the Sm-doped cerium oxides have better catalytic performance for their lower catalytic temperature, especially the $\mathrm{P}_{3}\left(\mathrm{Ce}_{0.76} \mathrm{Sm}_{0.24} \mathrm{O}_{2}\right)$. The conversion rate of commercial ceria has failed to reach $40 \%$ at $300^{\circ} \mathrm{C},{ }^{24,31}$ while all products have achieved at least $70 \%$ and the $\mathrm{P}_{3}$ has achieved full conversion. Due to the large surface area $\mathrm{P}_{3}$ can provide more active sites for conversion, which can be one of the results of high catalytic performance. Figure 8 shows the catalytic performance of $\mathrm{P}_{1}-\mathrm{P}_{6}$, respectively, and it is seen that the performance becomes better from $\mathrm{P}_{1}$ to $\mathrm{P}_{3}$, but worse then. This phenomenon can be supported by Raman spectra, and explained that the $\mathrm{P}_{3}$ has the most lattice defect, which is in favour of the adsorption and desorption of gas molecules on the surface of catalyst.

\section{Conclusion}

In summary, a series of $\mathrm{Sm}^{3+}$-doped $\mathrm{CeO}_{2}$ nanospheres by a one-step hydrothermal method was obtained. The morphology and structures of products change as the doping amount increases and so does the catalytic performance. The samarium was doped into the ceria lattice successfully. The $\mathrm{Ce}_{0.76} \mathrm{Sm}_{0.24} \mathrm{O}_{2}$ has the best catalytic performance among the series of product as it has the most oxygen vacancies and large surface area. As a catalyst with lower cost and better catalytic efficiency, the samariumdoped nanocerium oxide has potential applications for $\mathrm{CO}$ oxidation.

\section{Acknowledgements}

This work was supported by the Natural Science Foundation of China (Grant 21276142), and Personnel Training Funds in National Basic Sciences (Grant J1103314).

\section{References}

1. Yahiro H et al 1988 J. Appl. Electrochem. 18527

2. Reddy B M et al 2008 Catal. Lett. 123327

3. Ju J, Chen F and Xia C 2014 Electrochim. Acta 136422

4. Di J et al 2010 J. Power Sources 1954695

5. Chen D et al 2013 Electrochem. Commun. 35131

6. Lee J M et al 2014 J. Appl. Electrochem. 44581

7. Mandal S et al 2013 Appl. Catal. A: Gen. 45294

8. Sutradhar $\mathrm{N}$ et al 2011 J. Phys. Chem. C: Nanomater. Interfaces $\mathbf{1 1 5} 7628$

9. Miedziak P J et al 2009 J. Mater. Chem. 198619

10. Sun Z et al 2010 J. Mater. Chem. 201947

11. Srinivasan R and Chandra B A 2010 Mater. Lett. 641954

12. Ma Y et al 2010 Adv. Mater. 221640

13. Ma Y et al 2010 J. Hazard Mater. 182386

14. Tao F F 2012 Chem. Commun. 483812

15. Hu C H et al 2011 Bull. Mater. Sci. 341033

16. Park D J et al 2011 J. Solid State Chem. 1842695

17. Wanger C D, Biggs W M and Davis L E 1979 Handbook of $X$-ray photoelectron spectroscopy (USA: Perkin-Elmer Corporation Physical Electronics Division)

18. Costescu R M et al 2012 J. Mater. Sci. 477225

19. Nguyen T D, Dinh C T and Do T O 2009 Langmuir 25 11142

20. Huang D G et al 2009 J. Phys. Chem. Solids 70853

21. Wang X et al 2012 Chem. Commun. 482885

22. Spanier J E et al 2001 Phys. Rev. B 64245407

23. McBride J R et al 1994 J. Appl. Phys. 762435

24. Liu W et al 2014 Nanoscale 610693

25. Choudhury B and Choudhury A 2013 Curr. Appl. Phys. 13217

26. Yen $\mathrm{H}$ et al 2012 Angew. Chem. Int. Ed. Engl. 5112032

27. Shan W, Shen W and Li C 2003 Adv. Mater. 154761

28. Weber W H, Hass K C and McBride J R 1993 Phys. Rev. B 48178

29. Wu Z, Li M and Overbury S H 2012 J. Catal. 28561

30. Livneh T and Sterer E 2006 Phys. Rev. B 73085118

31. Liu W et al 2013 J. Mater. Chem. A 16942 